\title{
A REPRESENTAÇÃO POLÍTICA DOS ESTADOS NA FEDERAÇÃO BRASILEIRA*
}

\author{
Márcia Miranda Soares \\ Luiz Cláudio Lourenço
}

\section{Introdução}

A proporcionalidade na representação política é um tema importante nas literaturas internacional e nacional dedicadas aos sistemas eleitorais. No Brasil, o tema está em voga nos meios de comunicação, na plataforma de políticos e no meio acadêmico, alimentado pelo debate sobre reforma política. O ponto mais destacado é a forma como os estados brasileiros se encontram representados na Câmara dos Deputados, sendo objeto de crítica o peso desigual que tem o voto dos eleitores, dentro das diferentes unidades da Federação, quando escolhem os deputados federais. A contraposição

* Este artigo é uma versão do trabalho apresentado no III Encontro da Associação Brasileira de Ciência Política (ABCP), 28-31 de julho de 2002, UFF, Niterói.

Artigo recebido em junho/2003

Aprovado em julho/2004 entre o eleitor do Acre ou Rondônia e o eleitor de São Paulo é um exemplo recorrente.

O presente artigo tem o objetivo de contribuir para esse debate, apresentando alguns aspectos envolvidos na representação dos estados brasileiros no legislativo nacional. Para esse fim, está organizado em duas partes: a primeira analisa a relação entre democracia, federalismo e representação política; a segunda apresenta as possíveis causas e conseqüências da desproporcionalidade na Câmara dos Deputados, destacando o impacto da criação de novos estados.

A principal conclusão é que, em nome de uma democracia federal mais inclusiva (consociativa), é defensável algum grau de desproporcionalidade em termos de população dos estados e cadeiras parlamentares, inclusive como mecanismo para evitar a tirania da maioria. Contudo, isso não significa que ajustes não possam ser feitos no nosso sistema de representação, tanto na defini- 
ção do piso e do teto na representação dos estados, como em fatores do sistema eleitoral que geram desproporcionalidade na representação dos partidos políticos: o quociente eleitoral, a fórmula D'Hont e as coligações eleitorais.

Por fim, um aspecto que foge às regras de representação mas que tem impacto direto sobre a desproporcionalidade deve ser considerado e criticado, a saber, a criação indiscriminada de estados, de perfil pobre e pouco populoso.

\section{Democracia, federalismo e represen- tação política}

O federalismo é provavelmente a forma mais clássica e o exemplo por excelência de recurso ao princípio envolvido no modelo consociativo. Não faz sentido, portanto, pretender aplicar à organização federativa o igualitarismo majoritário ou plebiscitário que vem sendo apregoado com tanto furor, o qual desconhece as coletividades intermediárias e se refere ao nivel dos indivíduos. Naturalmente, é possivel observar que o Senado é o lugar previsto, em nossa aparelhagem institucional, para a aplicação do princípio consociativo, assegurando-se ali a representação dos estados como tal. Contudo, é discutivel, em primeiro lugar, que disso decorra a possibilidade de se ignorar inteiramente aquele princípio no plano da Câmara dos Deputados (Reis, 1993, pp. 162-163).

O principal argumento a favor de uma representação estritamente proporcional em termos de população e cadeiras parlamentares seria o seu caráter mais democrático. A alocação desproporcional de cadeiras, segundo a população, infringiria a tradução mais precisa do princípio igualitário da democracia expressa na equação: 1 (um) indivíduo $=1$ (um) voto.

No caso brasileiro, a desproporcionalidade decorre, principalmente, da legislação eleitoral que define os estados como distritos e estabelece um patamar mínimo e máximo para a representação destes na câmara baixa: respectivamente oito e setenta deputados federais. O resultado, segundo os críticos, é a violação do princípio igualitário da democracia, com os votos de alguns cidadãos tendo maior valor: o eleitor de Roraima ou do Acre em comparação com o de São Paulo, para citar os casos mais extremos. A conclusão é que o aperfeiçoamento da democracia exigiria a representação igualitária dos cidadãos, ou seja, a correspondência entre o percentual de população e o de deputados federais em cada estado de nossa federação.

A principal objeção a esse argumento é seu entendimento de democracia, que considera tão-somente a dimensão individual da representação e o princípio majoritário. Podemos defender uma outra concepção, na qual a regra da maioria é apenas um expediente a serviço da democracia, e não um fim em si mesmo; e que privilegie a inclusão e o consenso, dando expressão a interesses relevantes presentes na sociedade, mesmo que minoritários.

Essas concepções expressam o que Lijphart (1999), a partir da observação do funcionamento da democracia em 36 países, distinguiu como modelo majoritário e modelo consociativo de democracia. O autor defende que em sociedades plurais o poder da maioria não somente é menos democrático, porque exclui minorias relevantes do poder, relegando-as ao papel de oposição, como também, ao fazer isso, pode ser fator de instabilidade política.

A federação é apontada por Lijphart como um dos freios ao poder da maioria, expressando o princípio consociativo ao definir a representação não apenas em termos individuais, mas também em termos territoriais. O sistema federal enfatiza a representação territorial ao garantir certa autonomia política às subunidades nacionais e ao incorporar a representação dessas subunidades no poder central. Com isso, temos uma dualidade na representação política das federações e um dilema: tornar as regiões politicamente mais iguais ou tornar todos os cidadãos (membros do corpo político nacional) mais iguais. As federações, e mesmo alguns estados unitários, convivem com esse dilema e buscam um equilíbrio. Assim, a razão para diminuir o grau de igualdade na representação dos indivíduos é incrementar a igualdade de representação das regiões (dos estados).

Dado isto, falar em proporcionalidade em federações requer distinguir entre a proporcionalidade do princípio territorial de representação e a proporcionalidade do princípio de representação dos cidadãos. 
O grau de igualdade na representação de regiões com perfis populacionais distintos equivale ao grau de desproporcionalidade dos cidadãos entre essas regiões. Disso decorre, como salienta King (1993), que regiões menores e mais vulneráveis são incorporadas a um preço proporcionalmente maior para os membros de outras regiões, e isso é aceito em nome dos benefícios advindos da união em uma coletividade mais ampla. Em suma, a federação destaca interesses de natureza territorial na representação política e, com isso, envolve sempre algum grau de desproporcionalidade na representação dos cidadãos na esfera nacional.

Essa problemática esteve na origem do sistema federal nos Estados Unidos, no final do século XVIII, e a solução encontrada foi o bicameralismo: uma casa legislativa representaria os interesses estaduais e outra os interesses dos indivíduos, considerados nacionalmente. Contudo, na atualidade, a existência de uma segunda câmara não exclui outras possibilidades de representação dos interesses territoriais, até porque o Senado tem tido peso e funções muito distintas entre os países; casos como a Bélgica, a Suíça e o Canadá mostram como a representação de grupos sociais relevantes pode ter vigência nas duas casas legislativas e até mesmo nas coalizões de governo do executivo nacional.

Para o caso brasileiro, dada a forma como estão estruturadas e atuam as duas casas legislativas, com ampla sobreposição de competências, ${ }^{1}$ inclusive daquelas mais diretamente relacionadas aos interesses federativos, não temos por que ignorar, como destaca a epígrafe acima, o princípio de representação territorial na câmara baixa.

Em suma, se o federalismo é algo importante e deve ser valorizado na estrutura de Estado no Brasil, e se os estados são unidades territoriais que têm relevância, então não há por que pretender uma representação estritamente proporcional, no sentido populacional, desconsiderando os interesses territoriais na constituição da câmara baixa.

\section{Causas e conseqüências da desproporcionalidade}

Como deve estar claro, a desproporcionalidade consiste na distorção entre a população dos distri- tos eleitorais (estados) e as cadeiras destinadas a esses distritos na câmara baixa. Passaremos a nos referir a essa desproporcionalidade como distrital, enfatizando o aspecto da representação territorial. Para calcular a desproporcionalidade distrital, seguindo outros autores (Samuels e Snyder, 2001; Nicolau, 2003), utilizaremos uma adaptação da fórmula de Loosemore e Hamby para o cálculo do Indice $D$, que aqui passa a ser denominado índice Dd (desproporcionalidade distrital):

$$
\mathrm{Dd}=1 / 2 \mathrm{~S}|\mathrm{ci}-\mathrm{pi}|
$$

onde c é o percentual de cadeira de um distrito $\mathbf{i}$, e $\mathbf{p}$ é o percentual da população dessa mesma unidade $\mathbf{i}$, em determinado ano eleitoral.

O trabalho de Samuels e Snyder (2001) permite situar o Brasil, em termos de desproporcionalidade distrital, no contexto internacional. Na Tabela 1 observamos que, à exceção de Holanda, Israel e Peru, que realizam as eleições legislativas em um único distrito nacional, e por conseguinte apresentam perfeita proporcionalidade, algum grau de desproporcionalidade é sempre observado em países que subdividem o território nacional em distritos eleitorais. Portanto, a questão relevante não é quem é desproporcional, mas qual o grau dessa desproporcionalidade, suas causas e conseqüências.

Em termos de intensidade, observamos que os países federativos e unitários apresentam médias semelhantes em desproporcionalidade distrital e que nos dois grupos há uma variação muito grande entre os países. Isso dificulta a formulação de uma explicação geral para as diferenças observadas. ${ }^{2}$

O Brasil está acima da média, situando-se entre os de maior desproporcionalidade distrital (9\%). Mas o que dizer desse número? Não temos como responder a essa questão tendo como referência o pouco que a literatura nos apresenta sobre outros países. Assim, o caminho mais plausível parece ser nos concentrar no caso brasileiro, analisando as possíveis causas e conseqüências da desproporcionalidade observada, o que pode contribuir para um debate mais consistente, afastando diagnósticos apressados e apontando alguns caminhos para o aperfeiçoamento do nosso sistema de representação. 
Tabela 1

Índice de Desproporcionalidade Distrital (Dd) na Câmara Baixa em 40 democracias

\begin{tabular}{|c|c|c|}
\hline Unitárias & & \\
\hline & Dd (\%) & Ano \\
\hline Holanda & 0 & 1996 \\
\hline Israel & 0 & 1999 \\
\hline Peru & 0 & 1993 \\
\hline Finlândia & 1 & 1991 \\
\hline Itália & 1 & 1996 \\
\hline Suécia & 1 & 1998 \\
\hline Ucrânia & 1 & 1998 \\
\hline Nova Zelândia & 2 & 1997 \\
\hline Polônia & 2 & 1997 \\
\hline Portugal & 2 & 1995 \\
\hline Hungria & 3 & 1998 \\
\hline Uruguai & 3 & 1992 \\
\hline Romênia & 4 & 1996 \\
\hline Grécia & 4 & 1997 \\
\hline Dinamarca & 5 & 1997 \\
\hline Grã-Bretanha & 5 & 1997 \\
\hline Japão & 5 & 1995 \\
\hline Tailândia & 5 & 1996 \\
\hline França & 7 & 1998 \\
\hline Noruega & 7 & 1993 \\
\hline Turquia & 9 & 1995 \\
\hline Chile & 15 & 1997 \\
\hline Bolívia & 17 & 1997 \\
\hline Islândia & 17 & 1995 \\
\hline Equador & 20 & 1998 \\
\hline Coréia & 21 & 1996 \\
\hline Média & 6,0 & \\
\hline Desvio Padrão & 6,5 & \\
\hline \multicolumn{3}{|l|}{ Federativas } \\
\hline Estados Unidos & 1 & 1992 \\
\hline Austrália & 2 & 1996 \\
\hline Suíça & 2 & 1995 \\
\hline África do Sul & 3 & 1995 \\
\hline Alemanha & 3 & 1994 \\
\hline Rússia & 4 & 1995 \\
\hline Áustria & 6 & 1994 \\
\hline Índia & 6 & 1991 \\
\hline México & 6 & 1997 \\
\hline Venezuela & 7 & 1996 \\
\hline Canadá & 8 & 1997 \\
\hline Brasil & 9 & 1998 \\
\hline Espanha & 10 & 1996 \\
\hline Argentina & 14 & 1995 \\
\hline Média & 5,8 & \\
\hline Desvio Padrão & 3,6 & \\
\hline
\end{tabular}

Fonte: Adaptado de Samuels e Snyder (2001, pp. 660-661).

\section{Causas da desproporcionalidade}

Regras eleitorais: piso e teto na representação dos estados

Em 1977, sob o governo autoritário-militar iniciado em 1964, a Emenda Constitucional no 8 estabeleceu um número mínimo (6) e máximo (55) de representantes, por estado, na Câmara dos Deputados. Esta Emenda garantiu ainda dois representantes para cada um dos territórios federais. A Emenda Constitucional n ${ }^{\circ} 22$, de 1982, alterou esses números: os estados passaram a ter como piso oito e como teto sessenta representantes, sendo que os territórios aumentaram seu piso para quatro deputados. No processo de redemocratização, a Constituição de 1988 somente alterou o limite máximo de representantes por estado, que passou a ser setenta.

O estabelecimento desses patamares de representação para os estados serviu como argumento para aqueles que caracterizaram o "problema" da nossa desproporcionalidade como um fenômeno derivado da ação dos militares, no final da década de 1970, com propósitos eleitorais. As emendas constitucionais acima citadas teriam levado à sobre-representação dos estados do Norte, do Nordeste e do Centro-Oeste, onde o partido de apoio aos militares era mais forte (Arena), e à sub-representação do Sudeste e do Sul, onde estava a principal base eleitoral do partido de oposição ao governo (MDB).

Contrariando esse argumento, Nicolau (1997) mostrou que a desproporcionalidade foi uma constante em nossa história política, não sendo maior no período da ditadura militar. Também é fato, como verificamos na Tabela 2, que os dados de desproporcionalidade, agregados por região, não confirmam essas conclusões. As regiões Nordeste e Centro-Oeste não apresentaram alterações significativas no grau de sobre-representação durante o período militar; e somente a região Norte aumentou significativamente sua sobre-representação a partir de 1978 - o que é explicado pela combinação entre as regras de piso e teto e a criação de novos estados na região, algo que teve vigor não somente no período autoritário, mas tam- 
Tabela 2

Distorção Percentual no Número de Cadeiras*, por anos selecionados e regiões do país (1947-2002)

\begin{tabular}{l|c|c|c|c|c}
\hline Ano & Sudeste & Nordeste & Norte & Centro-Oeste & Sul \\
\hline 1947 & $-4,6$ & $+1,5$ & $+3,3$ & $+1,4$ & $-1,5$ \\
1950 & $-4,3$ & $+1,6$ & $+3,4$ & $+1,3$ & $-1,9$ \\
1954 & $-5,5$ & $+2,6$ & $+2,8$ & $+1,0$ & $-1,0$ \\
1958 & $-5,5$ & $+3,7$ & $+2,8$ & $+0,7$ & $-1,7$ \\
1962 & $-4,9$ & $+1,7$ & $+2,9$ & $+0,7$ & $-0,4$ \\
1966 & $-4,7$ & $+2,3$ & $+2,8$ & $+0,3$ & $-0,7$ \\
1970 & $-3,1$ & $-1,2$ & $+1,9$ & 0 & $+2,3$ \\
1974 & $-5,7$ & $-0,6$ & $+1,5$ & $+0,5$ & $+4,3$ \\
1978 & $-6,1$ & $+0,6$ & $+2,0$ & $+0,3$ & $+3,2$ \\
1982 & $-8,1$ & $+1,9$ & $+4,7$ & $+0,3$ & $+1,3$ \\
1986 & $-8,5$ & $+1,8$ & $+4,4$ & $+2,1$ & $+0,3$ \\
1990 & $-9,1$ & $+1,1$ & $+6,1$ & $+1,8$ & $+0,2$ \\
1994 & $-7,7$ & $+0,7$ & $+5,6$ & $+1,5$ & $+0,1$ \\
1998 & $-7,8$ & $+0,9$ & $+5,5$ & $+1,3$ & 0 \\
2002 & $-7,8$ & $+1,3$ & $+5,1$ & $+1,1$ & $+0,2$ \\
\hline
\end{tabular}

* Diferença entre o percentual de população e cadeiras parlamentares nas regiôes brasileiras.

Fonte: Adaptado e atualizado de Nicolau (1997).

bém no período democrático mais recente. Voltaremos a este ponto mais adiante. A região Sul foi continuamente sobre-representada no período pós-1970. Por fim, a região Sudeste sempre foi sub-representada, algo que se tornou mais pronunciado a partir de 1978, o que pode ser interpretado como a contrapartida da criação dos novos estados na região Norte.

\section{A criação de novos estados}

A sub-representação de São Paulo, com um déficit de 42 cadeiras nas últimas eleições parlamentares, como mostra a Tabela 3, é o fator que mais contribuiu para nossa desproporcionalidade. A desproporcionalidade distrital (Dd) calculada para 2002 permaneceu em 9\% e, analisando os dados desagregados, verificamos que a sub-representação de São Paulo respondeu por 4\% desse índice, ou seja, mais de $40 \%$ da desproporcionalidade observada.

Mas há outro fator relevante e pouco considerado entre as causas da desproporcionalidade na nossa representação política: os novos estados, cria- dos principalmente a partir da década de 1980. Em 1962, o Acre deixou a condição de território para se tornar estado; em 1979 foi criado o estado de Mato Grosso do Sul, a partir do desmembramento do estado do Mato Grosso. Na década de 1980, surgiram quatro novos estados: o território de Rondônia elevou-se à categoria de estado em 1981; o mesmo ocorreu com Roraima e Amapá na Constituição de 1988, quando também se criou o estado de Tocantins com a divisão do estado de Goiás.

Todos os novos estados são pobres e pouco populosos, ${ }^{3}$ o que combinado com a garantia de um piso mínimo de oito representantes, resultou no que observamos na Tabela 3: cinco desses seis novos estados estão no topo dos que detém maior sobre-representação política na Câmara dos Deputados, somando uma sobre-representação de 28 cadeiras. Juntos, os seis estados respondem por $3 \%$ dos $9 \%$ da desproporcionalidade distrital, ou seja, mais de $30 \%$ do total.

O estabelecimento de piso e teto na representação dos estados, combinado com a criação de novos estados, alterou significativamente a desproporcionalidade entre as regiões. Voltando a Tabela 2, vemos que o Norte tem aumento expressi- 
vo na sua representação parlamentar a partir de 1978, atingido o ápice de sobre-representação em 1990 (+6,1), primeira eleição legislativa após a Constituição de 1988, quando a região ganhou três novos estados. A contrapartida parece ser a perda relativa de representação da região Sudeste no mesmo período, com o ápice de sub-representação situado na mesma eleição de $1990(-9,1)$.
Cabe ressaltar que os novos estados têm impactos ainda mais profundos na representação do Senado, que é paritária entre os estados. Seis novos estados significaram dezoito cadeiras adicionais no Senado, o que subverteu a representação política dos outros estados.

A criação de novos estados é motivada pelas vantagens políticas e econômicas proporcionadas a

Tabela 3

Representação dos Estados na Câmara dos Deputados (2002)

\begin{tabular}{|c|c|c|c|c|}
\hline Estado & População* & $\begin{array}{l}\text { Representação } \\
\text { Corrente } \\
\text { (A) }\end{array}$ & $\begin{array}{l}\text { Representação } \\
\text { Proporcional** } \\
\text { (B) }\end{array}$ & $\begin{array}{c}\text { Diferença } \\
\text { (A-B) }\end{array}$ \\
\hline Acre & 557.526 & 8 & 2 & +6 \\
\hline Amapá & 477.032 & 8 & 1 & +7 \\
\hline Roraima & 324.397 & 8 & 1 & +7 \\
\hline Tocantins & 1.157 .098 & 8 & 4 & +4 \\
\hline Rondônia & 1.379 .787 & 8 & 4 & +4 \\
\hline Pará & 6.192 .307 & 17 & 19 & -2 \\
\hline Amazonas & 2.812 .557 & 8 & 9 & -1 \\
\hline Norte & 12.900 .704 & 65 & 40 & +25 \\
\hline Sergipe & 1.784 .475 & 8 & 5 & +3 \\
\hline Piauí & 2.843 .278 & 10 & 9 & +1 \\
\hline Paraíba & 3.443 .825 & 12 & 10 & +2 \\
\hline Maranhão & 5.651 .475 & 18 & 17 & +1 \\
\hline R. G. do Norte & 2.776 .782 & 8 & 8 & 0 \\
\hline Alagoas & 2.822 .621 & 9 & 9 & 0 \\
\hline Ceará & 7.430 .661 & 22 & 22 & 0 \\
\hline Pernambuco & 7.918 .344 & 25 & 24 & +1 \\
\hline Bahia & 13.070 .250 & 39 & 40 & -1 \\
\hline Nordeste & 47.741 .711 & 151 & 144 & +7 \\
\hline Goiás & 5.003 .228 & 17 & 15 & +2 \\
\hline Distrito Federal & 2.051 .146 & 8 & 6 & +2 \\
\hline M. G. do Sul & 2.078 .001 & 8 & 6 & +2 \\
\hline Mato Grosso & 2.504 .353 & 8 & 8 & 0 \\
\hline Centro- Oeste & 11.636 .728 & 41 & 35 & +6 \\
\hline Rio de Janeiro & 14.391 .282 & 46 & 43 & +3 \\
\hline Espírito Santo & 3.097 .232 & 10 & 9 & +1 \\
\hline Minas Gerais & 17.891 .494 & 53 & 54 & -1 \\
\hline São Paulo & 37.032 .403 & 70 & 112 & -42 \\
\hline Sudeste & 72.412 .411 & 179 & 218 & -39 \\
\hline Paraná & 9.563 .458 & 30 & 29 & +1 \\
\hline Santa Catarina & 5.356 .360 & 16 & 16 & 0 \\
\hline R. G. do Sul & 10.187 .798 & 31 & 31 & 0 \\
\hline Sul & 25.107 .616 & 77 & 76 & +1 \\
\hline Brasil & 169.799 .170 & 513 & 513 & $\mathbf{0}$ \\
\hline
\end{tabular}

${ }^{*}$ Censo Demográfico 2000, IBGE: www.ibge.gov.br.

** Representação dos estados proporcional à população e por maiores sobras.

Fonte: Atualizada de Nicolau (2003, p. 209). 
qualquer localidade que se torna um estado, sobretudo as menos populosas e mais pobres. A principal vantagem política é o aumento da representação política no governo federal: três senadores e oito deputados federais. Entre as vantagens econômicas destacam-se: a assunção de competências tributárias exclusivas - Imposto sobre a Propriedade de Veículos Automotores (IPVA), Imposto sobre a Circulação de Mercadoria e Serviços (ICMS) e Imposto sobre a Transmissão de Bens Imóveis Causa Mortis (ITCD); a garantia de uma cota-parte do Fundo de Participação dos Estados (FPE); e uma maior força política para barganhar recursos junto ao governo Federal. Em suma, a lógica dessas vantagens é extremamente perversa, quanto menos populosa e mais pobre a região, maiores os incentivos em se tornar estado, sem contar que uma região com essas características parece encontrar menos empecilhos para atingir tal objetivo. ${ }^{5}$

A Constituição de 1988 condiciona à criação de novos estados a aspectos estritamente políticos, não estabelecendo nenhuma exigência demográfica ou econômica:

Os Estados podem incorporar-se entre si, subdividir-se ou desmembrar-se para se anexarem a outros, ou formarem novos Estados ou Territórios Federais, mediante aprovação da população diretamente interessada, através de plebiscito, e do Congresso Nacional, por lei complementar (Capítulo 1, Art.18, $\$ 3^{\circ}$ da Constituição da República Federativa do Brasil de 1988).

A criação de estados é um tema pouco explorado no debate político nacional, apesar de sua constante presença na agenda legislativa, como verificamos na Tabela 4.

Considerando o período que segue à Constituição de 1988, da década de 1990 até o final de 2003 , temos atualmente dezessete projetos em tramitação no Congresso visando à criação de novos estados e territórios. A região Norte lidera o ranking com sete projetos, seguida pelas regiões Centro-Oeste (5), Sudeste (4) e Nordeste (2).

$\mathrm{Na}$ atual legislatura, em 15 de outubro de 2003, foi criada a Frente Parlamentar para Criação de Novos Estados, cuja função manifesta é verifi- car a viabilidade para criação de novos estados. $\mathrm{Na}$ verdade, a Frente parece funcionar como instrumento de articulação política visando à criação de estados, pobres e pouco populosos, como fica claro no depoimento de seu fundador, o deputado Ronaldo Dimas (PSDB - TO): "O que nós queremos é que os estados maiores, onde a administração pública torna-se inviável, sejam divididos para dar oportunidade de crescimento e desenvolvimento para regiões abandonadas". ${ }^{6}$

A principal justificativa utilizada na defesa da redivisão territorial é o desenvolvimento econômico e social engendrado a uma região transformada em estado. Um dos exemplos utilizados nas justificativas dos projetos apresentados é o desenvolvimento de Tocantins a partir de sua autonomia política em 1988.

O que é controverso são os benefícios para o país das mudanças em suas fronteiras internas, tal qual têm sido conduzidas, em um momento de escasso crescimento econômico e de contenção dos gastos públicos. A criação de estados pobres e pouco populosos, além dos impactos sobre a representação política, significa perda de recursos fiscais para os estados já constituídos, debilitando o Fundo de Participação dos Estados (FPE) como mecanismo redistributivo. Também amplia o custeio com a máquina administrativa e de pessoal, ${ }^{7}$ em detrimento de gastos com políticas públicas.

No contrapé dessas iniciativas, como mostra a Tabela 4, dois projetos propõem alterações no texto constitucional, estabelecendo critérios mais restritivos à criação de novas unidades federais.

\section{Conseqüências da desproporcionalidade}

\section{Moderno versus retrógrado}

Uma visão difundida sobre as conseqüências da desproporcionalidade na representação dos estados sustenta que as forças mais retrógradas do país estariam sendo beneficiadas em detrimento dos interesses mais modernos. A sobre-representação do Norte, do Nordeste e do Centro-Oeste corresponderia à sobre-representação das forças polí- 
Tabela 4

Projetos Legislativos de Criação de Novos Territórios e

Estados no Brasil

(1990-2003)

\begin{tabular}{|c|c|c|c|c|c|c|c|}
\hline Ano & Autor & Partido & UF & Unidade a ser criada & $\begin{array}{l}\text { Referência do } \\
\text { projeto }\end{array}$ & $\begin{array}{l}\text { UF } \\
\text { Modifi- } \\
\text { cada }\end{array}$ & $\begin{array}{l}\text { Situação e regime de } \\
\text { tramitação }\end{array}$ \\
\hline & & & & REGIÃO NORTE & & & \\
\hline 1990 & $\begin{array}{c}\text { Comissão Mista } \\
\text { do Congresso } \\
\text { Nacional }\end{array}$ & - & - & Estado de Tapajós & ADL-1/90 & PA & $\begin{array}{l}\text { Aguardando parecer } \\
\text { (prioridade) }\end{array}$ \\
\hline 1999 & $\begin{array}{l}\text { Sen. Mozarildo } \\
\text { Cavalcanti }\end{array}$ & PPS & $\mathrm{RR}$ & Território Federal de Solimões & PDS-20/99 & $\mathrm{AM}$ & $\begin{array}{l}\text { Aguardando parecer } \\
\text { (prioridade) }\end{array}$ \\
\hline 1999 & $\begin{array}{l}\text { Sen. Mozarildo } \\
\text { Cavalcanti }\end{array}$ & PPS & RR & Estado de Tapajós & PDS-19/99 & PA & $\begin{array}{l}\text { Pronta para pauta } \\
\text { (prioridade) }\end{array}$ \\
\hline 2000 & \begin{tabular}{|l} 
Sen. Sebastião da \\
Rocha \\
\end{tabular} & PDT & $\mathrm{AP}$ & Território Federal do Oiapoque & PDS-274/00 & $\mathrm{AP}$ & $\begin{array}{l}\text { Aguardando parecer } \\
\text { (prioridade) }\end{array}$ \\
\hline 1991 & $\begin{array}{c}\text { Dep. Hilário } \\
\text { Coimbra }\end{array}$ & PTB & $\mathrm{AP}$ & Estado de Tapajós & PDC-120/91 & PA & $\begin{array}{l}\text { Pronta para pauta } \\
\text { (ordinária) }\end{array}$ \\
\hline 1992 & $\begin{array}{l}\text { Dep. Giovani } \\
\text { Queiroz }\end{array}$ & PDT & PA & Estado de Carajás & PDC-159/92 & PA & $\begin{array}{l}\text { Pronta para pauta } \\
\text { (ordinária) }\end{array}$ \\
\hline \multirow[t]{2}{*}{2001} & $\begin{array}{l}\text { Dep. Sebastião } \\
\text { Madeira }\end{array}$ & PSDB & MA & Estado do Maranhão do Sul & PDC-947/01 & MA & $\begin{array}{l}\text { Pronta para pauta } \\
\text { (ordinária) }\end{array}$ \\
\hline & & & & REGIÃO CENTRO-OESTE & & & \\
\hline 2001 & $\begin{array}{l}\text { Sen. Mozarildo } \\
\text { Cavalcanti }\end{array}$ & PPS & $\mathrm{RR}$ & Estado do Araguaia & PDC-850/01 & MT & $\begin{array}{l}\text { Aguardando parecer } \\
\text { (prioridade) }\end{array}$ \\
\hline 2002 & $\begin{array}{l}\text { Sen. Francisco } \\
\text { Escórcio }\end{array}$ & PMDB & MA & Estado Planalto Central & PDS-298/02 & $\begin{array}{l}\text { MG- } \\
\text { GO }\end{array}$ & - \\
\hline 2003 & $\begin{array}{l}\text { Dep. Wellinton } \\
\text { Fagundes }\end{array}$ & PL & MT & $\begin{array}{l}\text { Estado do Araguaia e Mato Grosso } \\
\text { do Norte }\end{array}$ & PDC-49/03 & MT & $\begin{array}{c}\text { Tramitando em } \\
\text { conjunto (prioridade) }\end{array}$ \\
\hline 2000 & $\begin{array}{l}\text { Dep. Rogério } \\
\text { Silva }\end{array}$ & PPS & MT & Estado do Mato Grosso do Norte & PDC-606/00 & MT & $\begin{array}{l}\text { Pronta para pauta } \\
\text { (ordinária) }\end{array}$ \\
\hline \multirow[t]{2}{*}{2003} & $\begin{array}{l}\text { Dep. Rogério } \\
\text { Silva }\end{array}$ & PPS & MT & Estado do Mato Grosso do Norte & PDC-495/03 & MT & $\begin{array}{l}\text { Pronta para pauta } \\
\text { (urgência) }\end{array}$ \\
\hline & & & & REGIÃO NORDESTE & & & \\
\hline 1998 & $\begin{array}{l}\text { Dep. Gonzaga } \\
\text { Patriota }\end{array}$ & PSB & $\mathrm{PE}$ & Estado do Rio São Francisco & PDC-631/98 & $\mathrm{BA}$ & $\begin{array}{l}\text { Pronta para pauta } \\
\text { (ordinária) }\end{array}$ \\
\hline \multirow[t]{2}{*}{1994} & Dep. Paes Ladim & PFL & PI & Estado de Gurguéia & PDC-439/94 & PI & $\begin{array}{l}\text { Pronta para pauta } \\
\text { (ordinária) }\end{array}$ \\
\hline & & & & REGIÃO SUDESTE & & & \\
\hline 1990 & $\begin{array}{c}\text { Comissão Mista } \\
\text { do Congresso } \\
\text { Nacional } \\
\end{array}$ & - & - & Estado do Triângulo & ADL-2/90 & MG & - \\
\hline 2002 & $\begin{array}{l}\text { Dep. Bispo } \\
\text { Wanderval } \\
\end{array}$ & PL & $\mathrm{SP}$ & Estado de São Paulo do Leste & PDC-1963/02 & SP & $\begin{array}{l}\text { Aguardando prazo para } \\
\text { recurso (ordinária) }\end{array}$ \\
\hline 2002 & $\begin{array}{c}\text { Dep. Romeu } \\
\text { Queiroz }\end{array}$ & PTB & MG & Estado de Minas do Norte & PDC-2095/02 & MG & $\begin{array}{l}\text { Aguardando prazo para } \\
\text { recurso (ordinária) }\end{array}$ \\
\hline \multirow[t]{2}{*}{2003} & $\begin{array}{c}\text { Dep. José Divino } \\
\text { e André Luiz }\end{array}$ & PMDB & MG & Estado da Guanabara & PDC 295/03 & RJ & $\begin{array}{l}\text { CCJC: aguardando } \\
\text { devolução (ordinária) }\end{array}$ \\
\hline & & & & OUTROS & & & \\
\hline 2002 & $\begin{array}{l}\text { Dep. Vanessa } \\
\text { Grazziotin }\end{array}$ & PCdoB & $\mathrm{AM}$ & $\begin{array}{c}\text { Exige estudo ou avaliação técnica } \\
\text { que indique a viabilidade do } \\
\text { desmembramento, da anexação ou } \\
\text { da criação de novos estados e } \\
\text { território federais }\end{array}$ & PEC-521/02 & - & $\begin{array}{l}\text { CCJC: Pronta para } \\
\text { pauta }\end{array}$ \\
\hline 2002 & $\begin{array}{l}\text { Dep. Osmar } \\
\text { Serraglio }\end{array}$ & PMDB & PR & $\begin{array}{c}\text { Exige que toda a população } \\
\text { envolvida na incorporação, } \\
\text { desmembramento ou anexação para } \\
\text { criação de novos estados e territórios } \\
\text { aprove tais atos por plebiscito }\end{array}$ & PEC-525/02 & - & $\begin{array}{l}\text { CCJC: tramitando em } \\
\text { conjunto }\end{array}$ \\
\hline
\end{tabular}

Fonte: Câmara dos Deputados. Site http://www.camara.gov.br. 
ticas mais conservadoras, clientelísticas e retrógradas do país, em prejuízo das forças políticas mais avançadas situadas no Sudeste e no Sul. As três passagens que se seguem expõem essa visão:

[...] De forma que é na Câmara dos Deputados, cuja eleição se realiza pelo sistema de representação proporcional, que está o problema, uma vez que a regra da proporcionalidade não é de fato obedecida. Isso porque a Constituição estabelece o direito de os Estados terem um mínimo de oito representantes e os proíbe de ter um número superior a setenta. O resultado é a sobre-representacão dos Estados das regiões Norte e Centro-Oeste e a sub-representação dos Estados da região Sudeste, que coincidentemente são os Estados mais dinâmicos do país - seja do ponto de vista econômico-financeiro, tecnológico, cultural, seja do ponto de vista político [...] (Kinzo, 1997, pp. 23-24).

Ao aumentar artificialmente a representação política de uma cultura política tradicional, atrasada, dominada por líderes locais, latifundistas, proprietários rurais e coronéis ou pessoas de sua escolha e confiança, o sistema eleitoral prejudicou a maioria da população dessas áreas. Ao sub-representar, no Congresso e no Senado, as áreas socialmente desenvolvidas e politicamente progressistas, a legislação diminuiu a possibilidade de aprovação, pela duas Casas, de reformas que viriam a beneficiar a maioria da população rural que habita principalmente estas áreas subdesenvolvidas. Tal foi o caso da reforma agrária (Soares, 2001, p. 294).

Do ponto de vista político, as diferenças entre os estados pobres, sobre-representados, e os mais ricos e sub-representados são bem nítidas. Os estados pobres são mais permeáveis a estilos clientelistas e patrimonialistas de políticas do que os mais ricos. A dominação personalista ainda é a regra de muitos lugares do Nordeste e do Norte. As organizações partidárias são fracas e as pessoas menos informadas e ligadas aos partidos (Mainwaring, 2001, p. 321).

Em primeiro lugar, é propício apontar certa contradição no debate da desproporcionalidade na representação legislativa dos estados. Por um lado, é reivindicada uma representação na Câmara dos Deputados que tenha como diretriz a população e não a região - busca-se a igualdade na representação dos cidadãos independentemente de sua localização territorial; por outro, a desproporcionalidade é referida como sendo regional: o Sudeste é o grande perdedor e os pequenos estados do Nordeste e do Norte são os grandes beneficiados. Se o que é enfatizado é a região, ou estado, então não há como pretender desvincular do debate sobre representação a questão federativa.

Mas dois são os pontos principais de vulnerabilidade de tais argumentos. O primeiro, já exposto anteriormente, diz respeito a quem é sub ou sobre representado. Como vimos, no período democrático mais recente a sobre-representação diz respeito sobretudo à região Norte e a sub-representação a um estado da região Sudeste: São Paulo. O segundo remete à contraposição entre a modernidade das forças políticas do Sul e do Sudeste e o arcaísmo das forças políticas das regiões Norte, Nordeste e Centro-Oeste. Essa postura para ser verdadeira teria que demonstrar, pelo menos, três coisas: a) que há dois "perfis" de representação na Câmara dos Deputados, um correspondendo ao Norte, ao Nordeste e ao Centro-Oeste e outro correspondendo ao Sudeste e ao Sul; b) que esses "perfis" derivam de características sociais, econômicas e/ou políticas dessas regiões e correspondem a posições e comportamentos distintos (inclusive nas votações) na Câmara dos Deputados; e, por fim c) que essas posições podem ser classificadas em "avançadas" e "retrógradas".

Ainda que todos esses pontos fossem demonstrados, e considerando a remota hipótese de os vinte estados das regiões Norte, Nordeste e Centro-Oeste atuarem em uníssono, a força política na Câmara estaria praticamente equilibrada entre os dois "grupos": Norte, Nordeste e Centro-Oeste detém 257 deputados (50\%) e Sudeste e Sul 256 deputados (50\%).

Tudo isso aponta a complexidade dos fatores envolvidos neste assunto e a impropriedade de imputar padrões de comportamento legislativo a partir dos dados de desproporcionalidade distrital e de impressões sobre os estados e as regiões. Aliás, alguns trabalhos nessa área, como o de Fi- 
gueiredo e Limongi (2001), que examina o comportamento legislativo a partir das votações nominais, têm sustentado a tese de força do executivo nacional e das lideranças partidárias no processo legislativo nacional, com elevado grau de disciplina partidária ${ }^{8}$ no comportamento dos parlamentares na câmara baixa brasileira, na primeira e na segunda legislaturas da nova ordem constitucional (1989-1998), e o sucesso do Executivo nacional na aprovação de sua agenda legislativa. Em trabalho mais recente (Cheibub, Figueiredo e Limongi, 2002), os autores defendem que o federalismo não tem sido uma variável importante para explicar o comportamento legislativo, analisado a partir das votações nominais e da distribuição de recursos orçamentários. Os partidos políticos, organizados por meio de suas lideranças no Congresso, e o presidente, por meio de seus poderes legislativos e da formação de coalizões de governo, seriam as principais variáveis a explicar o comportamento legislativo.

\section{Representação dos partidos}

A representação dos distritos pode influenciar a representação dos partidos políticos na câmara baixa. Isto é, a desproporcionalidade distrital pode gerar desproporcionalidade na representação partidária:9 partidos com forte presença nos distritos sobre-representados são beneficiados e partidos com concentração de votos nos distritos sub-representados são prejudicados.

Verificamos na Tabela 5 que algum grau de desproporcionalidade na representação dos partidos $^{10}$ está presente nas principais democracias do mundo. No entanto, comparando com a Tabela 1 , três pontos merecem menção: 1) no geral, os países apresentam graus de desproporcionalidade distrital e partidária bastante distintos; 2) o grau de desproporcionalidade partidária parece estar mais diretamente relacionado ao sistema de representação (Majoritário, Proporcional ou Misto) do que à forma de Estado (Federal ou Unitária); e 3) o Brasil apresenta um índice de desproporcionalidade partidária abaixo da média, situando-se entre aqueles de melhor posicionamento (ver Tabela 5).
Tabela 5

Índice de Desproporcionalidade Partidária (Dp) na Câmara Baixa em 27 Democracias $(1995-2000)^{1}$

\begin{tabular}{|c|c|c|}
\hline \multirow[t]{2}{*}{ Unitárias } & \multirow[b]{2}{*}{ Dp (\%) } & \multirow[b]{2}{*}{$\begin{array}{c}\text { Sistema de } \\
\text { Representação }\end{array}$} \\
\hline & & \\
\hline Dinamarca & 2 & $\mathrm{P}$ \\
\hline Suécia & 3 & $\mathrm{P}$ \\
\hline Israel & 4 & $\mathrm{P}$ \\
\hline Nova Zelândia & 4 & $\mathrm{C}$ \\
\hline Taiwan & 5 & $\mathrm{C}$ \\
\hline Holanda & 5 & $\mathrm{P}$ \\
\hline Noruega & 5 & $\mathrm{P}$ \\
\hline República Tcheca & 11 & $\mathrm{P}$ \\
\hline Tailândia & 12 & $\mathrm{C}$ \\
\hline Japão & 14 & $\mathrm{C}$ \\
\hline Ucrânia & 14 & $\mathrm{C}$ \\
\hline Hungria & 14 & $\mathrm{C}$ \\
\hline Coréia & 16 & $\mathrm{C}$ \\
\hline Eslovênia & 16 & $\mathrm{P}$ \\
\hline Polônia & 18 & $\mathrm{P}$ \\
\hline Romênia & 18 & $\mathrm{P}$ \\
\hline Grã-Bretanha & 20 & M \\
\hline Média & 10,6 & \\
\hline Desvio Padrão & 6,2 & \\
\hline \multicolumn{3}{|l|}{ Federais } \\
\hline Bélgica & 4 & $\mathrm{P}$ \\
\hline Estados Unidos & 6 & M \\
\hline Alemanha & 6 & $\mathrm{C}$ \\
\hline Suíça & 7 & $\mathrm{P}$ \\
\hline Espanha & 7 & $\mathrm{P}$ \\
\hline Brasil $^{2}$ & 7 & $\mathrm{P}$ \\
\hline México & 8 & $\mathrm{C}$ \\
\hline Rússia & 11 & $\mathrm{C}$ \\
\hline Austrália & 16 & M \\
\hline Canadá & 17 & M \\
\hline Média & 8,9 & \\
\hline Desvio Padrão & 4,4 & \\
\hline
\end{tabular}

* P (Proporcional), M (Majoritário) e C (de Combinação ou Misto).

Fontes: 1. Norris (2004, p. 92); 2. Nicolau (2003, p. 223).

Mas o que podemos dizer da relação entre a desproporcionalidade distrital (Dd), descrita acima, e a desproporcionalidade partidária (Dp) observadas no caso brasileiro?

Em primeiro lugar, a desproporcionalidade distrital é apenas um dos fatores da nossa organização política determinante da desproporcionalidade partidária. Como mostra Nicolau (2003), 
três regras do sistema eleitoral brasileiro também respondem pelas distorções observadas no sistema representativo:

- Cláusula de exclusão (quociente eleitoral): a distribuição das cadeiras pelos partidos ou coligações tem como primeira etapa o cálculo do quociente eleitoral, que é o resultado da divisão do total dos votos válidos em um distrito (estado) pelo número de cadeiras designadas para esse distrito. Esse quociente eleitoral funciona como cláusula de exclusão, na medida em que os partidos que não atingirem este quociente não receberão quaisquer cadeiras.

- Fórmula Eleitoral D'Hont: divididas as cadeiras entre os partidos por meio do quociente eleitoral, as cadeiras remanescentes passam a ser distribuídas pela fórmula D'Hont: "o total de votos da cada partido ou coligação é dividido pelo número de cadeiras que ele já recebeu mais um: os partidos com as maiores médias recebem as cadeiras não alocadas na primeira etapa" (Nicolau, 2003, p. 204). Novamente, os beneficiados são os partidos que conseguiram as maiores votações.

- Coligações Eleitorais: As coligações são alianças eleitorais que, no cálculo para distribuição das cadeiras legislativas, funcionam como se fossem um único partido político. Assim, os votos nominais e de legenda contam indiscriminadamente para a coligação e não há um critério proporcional para a alocação partidária das cadeiras no interior das coligações. Isso faz com que na distribuição das cadeiras intracoligações um partido menor possa conseguir representação, mesmo tendo um patamar de votação inferior ao quociente eleitoral. As contrário dos outros dois fatores, as regras de coligação favorecem os pequenos partidos.

O trabalho de Nicolau (Idem, p. 203) também permite-nos dimensionar o impacto isolado da desproporcionalidade distrital sobre a desproporcionalidade partidária. Utilizando-se de um exercício de simulação, como base nos dados eleitorais de 1998, o autor mostra que se corrigidas as distorções produzidas pelos fatores acima citados a desproporcionalidade cairia de $7 \%$ para $4,1 \%$. Contudo, se fosse corrigida também a despropor- cionalidade distrital, o ganho de proporcionalidade partidária não seria significativo, de apenas 0,8 pontos percentuais, declinando a desproporcionalidade de $4,1 \%$ para $3,3 \%{ }^{11}$

Talvez mais importante que os índices apresentados seria analisar os dados desagregados, mostrando quais partidos têm sido beneficiados ou prejudicados, nos estados, pela desproporcionalidade distrital. A tarefa foge aos limites desse artigo e fica como sugestão para outra empreitada. Contudo, podemos adiantar uma hipótese a ser verificada: os benefícios de partidos como o PFL e o PMDB, que concentravam suas votações nos estados mais sobre-representandos, e as perdas de partidos como o PT, decorrentes de seu peso político em São Paulo, estão sendo diluídos pelo que podemos designar como um processo de nacionalização dos partidos políticos, ou seja, uma maior homogeneidade na votação dos principais partidos nas diversas unidades territoriais. Segundo Mainwaring e Jones (2001), todos os principais partidos políticos brasileiros aumentaram seu grau de nacionalização a partir de 1994, à exceção do PDT, que se manteve constante.

Um último comentário refere-se à confusão e, muitas vezes, incoerência nas posições dos "proporcionalistas". Assim, não é raro encontrarmos entre os que defendem a estrita proporcionalidade distrital, em nome da justiça igualitária, a defesa do estabelecimento de uma cláusula de exclusão (percentual mínimo de votação) para a entrada dos pequenos partidos na Câmara dos Deputados, o que significaria aumentar a desproporcionalidade partidária e esterilizar os votos dos cidadãos destinados a esses partidos.

\section{Desigualdades econômicas}

A problemática das enormes desigualdades econômicas estaduais presente na Federação brasileira não pode ser negligenciada. Uma representação proporcional dos estados na Câmara levaria a uma maior coincidência entre poder econômico e poder político, aumentando o grau de desequilíbrio federativo.

Isto é particularmente válido para o estado de São Paulo. Voltando à Tabela 3, verificamos que a correção das desproporcionalidades distritais ele- 
Tabela 6

Indicadores de Desigualdades Socioeconômicas entre Regiões

e Estados da Federação Brasileira (2001)

\begin{tabular}{|c|c|c|c|}
\hline Regiões e Estados & População (\%)* & $\begin{array}{c}\text { Participação } \\
\text { no PIB** }\end{array}$ & $\begin{array}{c}\text { PIB/per capita } \\
(\text { em R\$)** }\end{array}$ \\
\hline Acre & 0,3 & 0,2 & 3.345 \\
\hline Amapá & 0,3 & 0,2 & 4.517 \\
\hline Roraima & 0,2 & 0,1 & 3.615 \\
\hline Tocantins & 0,7 & 0,3 & 2.588 \\
\hline Rondônia & 0,8 & 0,5 & 4.321 \\
\hline Pará & 3,6 & 1,8 & 3.429 \\
\hline Amazonas & 1,7 & 1,7 & 7.150 \\
\hline Norte & 7,6 & 4,8 & 4.305 \\
\hline Sergipe & 1,1 & 0,7 & 4.514 \\
\hline Piauí & 1,7 & 0,5 & 1.940 \\
\hline Paraíba & 2,0 & 0,9 & 2.961 \\
\hline Maranhão & 3,3 & 0,9 & 1.796 \\
\hline Rio Grande do Norte & 1,6 & 0,8 & 3.493 \\
\hline Alagoas & 1,7 & 0,6 & 2.650 \\
\hline Ceará & 4,4 & 1,8 & 2.859 \\
\hline Pernambuco & 4,7 & 2,6 & 3.962 \\
\hline Bahia & 7,7 & 4,4 & 3.954 \\
\hline Nordeste & 28,1 & 13,1 & 3.255 \\
\hline Goiás & 2,9 & 2,1 & 4.903 \\
\hline Distrito Federal & 1,2 & 2,8 & 15.758 \\
\hline Mato Grosso do Sul & 1,2 & 1,1 & 6.507 \\
\hline Mato Grosso & 1,5 & 1,2 & 5.644 \\
\hline Centro-Oeste & 6,9 & 7,2 & 7.260 \\
\hline Rio de Janeiro & 8,5 & 12,3 & 10.168 \\
\hline Espírito Santo & 1,8 & 1,9 & 7.144 \\
\hline Minas Gerais & 10,5 & 9,5 & 6.263 \\
\hline São Paulo & 21,8 & 33,4 & 10.647 \\
\hline Sudeste & 42,6 & 57,1 & 9.320 \\
\hline Paraná & 5,6 & 6,1 & 7.506 \\
\hline Santa Catarina & 3,2 & 3,9 & 8.541 \\
\hline Rio Grande do Sul & 6,0 & 7,8 & 9.126 \\
\hline Sul & 14,8 & 17,8 & 8.384 \\
\hline Brasil & $100 \%$ & $100 \%$ & 6.954 \\
\hline
\end{tabular}

Fontes: *Censo Demográfico 2000, IBGE, www.ibge.gov.br; **Contas Regionais do Brasil, IBGE, www.ibge.gov.br.

varia para 112 o número de cadeiras parlamentares desse estado, ou seja, mais de $20 \%$ da representação da Câmara, e superior ao dobro da representação do segundo estado com maior número de cadeiras parlamentares $(M G=54)$, sem contar a diferença em relação aos estados menos populosos. O enorme poder econômico do estado está expresso na Tabela 6: em 2001, São Paulo detinha $33,4 \%$ do PIB brasileiro, quase o triplo do segundo estado em riquezas $(\mathrm{RJ}=12,3 \%)$ e muito superior à somatória das riquezas das regiões Norte, Nordeste e Centro-Oeste $(25,1 \%)$.

Não estamos defendendo que a sobre-representação dos estados mais pobres possa solucio- 
nar as suas mazelas socioeconômicas e produzir maior igualdade regional. O ponto que queremos frisar é tão-somente que a adoção de uma representação estritamente proporcional em termos populacional significaria o fortalecimento político de um estado que concentra mais de um terço das riquezas do país e o enfraquecimento político de estados pouco expressivos economicamente. O resultado seria maior desequilíbrio político na nossa Federação, o que nos remete mais uma vez para o problema da "tirania da maioria".

\section{Conclusão}

A defesa de uma representação estritamente proporcional, no sentido populacional, dos estados brasileiros na Câmara dos Deputados encontra respaldo no modelo de democracia majoritária. Se nos desviamos desse modelo e nos aproximamos do modelo de democracia consociativa, podemos pensar a federação como expressão de interesses territoriais relevantes que merecem representação especial, o que justifica abrir mão de total igualdade na representação política dos indivíduos em nome de uma maior igualdade na representação dos estados.

Também não há porque desvincular nossa câmara baixa do princípio de representação federativa, restringindo essa ao Senado, principalmente se levamos em conta as enormes disparidades socioeconômicas entre os estados e a sobreposição de competências nas duas casas legislativas.

Ao comparar o Brasil com outros países, verificamos que a desproporcionalidade distrital não é um privilégio nosso, ela está presente na maioria dos países - todos os que subdividem o território nacional para realizar eleições legislativas. Quanto ao grau de desproporcionalidade, o Brasil se encontra acima da média, mas nada nos permite concluir que o índice de desproporcionalidade brasileiro em si seja algo negativo, a merecer correções.

Analisando nossa desproporcionalidade distrital, observamos que ela envolve sobretudo a subrepresentação do estado de São Paulo e a sobrerepresentação da região Norte. Como principais causas, concluímos que o estabelecimento de piso e teto na representação dos estados só responde em parte pelos efeitos observados: é certo que o teto responde pela sub-representação de São Paulo, mas o piso privilegia sobretudo os mais novos estados da federação. Ou seja, a criação de estados pouco populosos e pobres nas últimas décadas é um fator importante para entendermos a desproporcionalidade distrital no Brasil.

Além do impacto negativo sobre a representação política, a criação de estados pobres e pouco populosos significa perda de recursos fiscais para os estados já constituídos, inclusive os mais pobres, e ampliação dos gastos com a máquina administrativa. Portanto, esse é um aspecto que merece melhor consideração, sobretudo quando constatamos a existência de vários projetos legislativos que propõem a criação de mais estados.

Quanto as conseqüências da desproporcionalidade na representação dos estados, consideramos impróprio e mesmo simplista o argumento de que a desproporcionalidade distrital estaria beneficiando as regiões mais retrógradas do país (Norte, Nordeste e Centro-Oeste), em detrimento dos centros mais modernos localizados no Sul e no Sudeste. Não há qualquer evidência empírica que possibilite imputar um padrão "retrógrado" ou "moderno" no comportamento dos legisladores das diferentes regiões brasileiras.

A relação entre a desproporcionalidade distrital e a desproporcionalidade partidária precisa ser melhor estudada. Expusemos que três outros fatores do nosso sistema eleitoral respondem pelas distorções na representação de nossos partidos políticos: a cláusula de exclusão (quociente eleitoral); a fórmula D'Hont e as coligações eleitorais. Estudos indicam que, corrigidas as desproporcionalidades geradas por esses fatores, pouco se ganharia, em termos de proporcionalidade partidária, com mudanças na representação dos estados.

Por fim, a representação estritamente proporcional dos estados, em termos de população, levaria a uma maior concentração de poder econômico e político em uma única unidade da Federação - o estado de São Paulo -, o que contribuiria para o aumento de nossos desequilíbrios federativos, com a conseqüente ameaça de o país ficar submetido no plano político-eleitoral ao que se denomina "tirania da maioria". 


\section{NOTAS}

1 Ambas as casas têm atribuições legislativas e fiscalizatórias parecidas. Várias iniciativas de lei do Senado necessitam de aprovação da Câmara dos Deputados e vive-versa. As pautas das duas casas estão fortemente ligadas e não é raro vermos as duas casas trabalhando matérias e até mesmo processos investigativos (CPIs) concomitantemente.

2 Nas correlações feitas por meio de regressão, Samuels e Snyder (2001) pouco conseguiram explicar da variação da desproporcionalidade na câmara baixa entre os países. A única correlação significativa foi com a variável magnitude distrital: sistemas de distrito uninominal (SDM) tendem a apresentar $4 \%$ a mais de desproporcionalidade na média.

3 O que pode ser constatado na Tabela 6 .

4 O FPE tem caráter redistributivo: a cota-parte de cada estado tem como principal critério definidor o fator inverso de sua renda per capita. A Lei Complementar 62, de 28/12/1989, determinou em seu artigo $2 \infty$ que $85 \%$ dos recursos deste Fundo deveriam ser destinados aos estados das regiões Norte, Nordeste e Centro-Oeste. A conclusão é evidente, ou seja, quanto mais pobre o estado (sobretudo se localizado nessas regiões), maiores as vantagens econômicas extraídas do FPE. Ver Aglas Watson Barrera e Maria Liz Medeiros Roarelli, "Relações fiscais intergovernamentais", em Affonso e Silva (1995, p. 138).

5 É exemplar a comparação entre o projeto de criação do estado do Triângulo Mineiro e do estado de Tocantins na Constituinte de 1988. Para Minas Gerais, perder o Triângulo Mineiro significava perder representação política no governo nacional e uma das regiões mais desenvolvidas do estado. Assim, o governador e os deputados de Minas Gerais, à exceção dos seis deputados da região, fizeram lobby e barganharam politicamente dentro do Congresso Nacional para que tal projeto fosse rejeitado. Ao contrário, a criação do estado de Tocantins, área de população reduzida e pouco desenvolvida economicamente, teve o apoio de dezoito dos vinte constituintes goianos (cf. Folha de S. Paulo, 27 de junho de 1988).

6 Fonte: Agência Câmara (23/4/2004).

7 Boa parte dos recursos federais que recebem esses estados é destinada ao sustento da máquina admi- nistrativa e do aparato institucional (secretarias de governo, assembléia legislativa, tribunal de contas, tribunal de justiça etc).

8 Disciplina partidária é medida pelo percentual de deputados que votam em acordo com a posição manifestada pelo líder do seu partido.

9 Na literatura internacional, autores como Samuels e Snyder (2001) diferenciam disproportionality, que se refere à desproporção entre porcentagem de votos e cadeiras recebidos pelos partidos, de malapportionment, que se refere à desproporção entre porcentagem de população e cadeiras dos distritos eleitorais de um país.

10 O cálculo da desproporcionalidade partidária foi feito adaptando-se o Índice $D$, de LoosemoreHamby: $\mathbf{D} \mathbf{p}=\mathbf{1} / \mathbf{2 S}|\mathbf{c j}-\mathbf{v j}|$, onde $\mathbf{c}$ é o percentual de cadeiras recebidas pelo partido $\mathbf{j}$, e $\mathbf{v}$ é o percentual de votos desse mesmo partido, em determinado ano eleitoral, considerando o total nacional.

11 Vale ainda lembrar que a correção da desproporcionalidade distrital levaria à diminuição da magnitude distrital $(M)$ em alguns estados, o que, seguindo as Leis de Duverger, aumentaria a desproporcionalidade na representação dos partidos.

\section{BIBLIOGRAFIA}

AFFONSO, Rui de Britto A. \& SILVA, Pedro Luiz Barros (orgs.). (1995), Federalismo no Brasil: reforma tributária e federação. São Paulo, Fundap/Unesp.

CHEIBUB, José Antonio; FIGUEIREDO, Argelina \& LIMONGI, Fernando. (2002), "Presidential agenda power and decision-making in presidential regimes: governors and politica parties in the Brazilian Congress". Trabalho apresentado no Encontro Anual da American Political Science Association, Boston.

FIGUEIREDO, Argelina \& LIMONGI, Fernando. (2001), Executivo e legislativo na nova ordem constitucional. 2 ed. Rio de Janeiro, FGV. 
KING, Preston. (1993), "Federation and representation", in Michael Burgess e GAGNON, Alain-G. Gagnon (eds.), Comparative federalism and federation: competing traditions and future directions, Harvester Wheatsheaf, Hertfordshire.

KINZO, Maria D’Alva Gil. (1997), "Governabilidade, estrutura institucional e processo decisório no Brasil”. Parceria Estratégi$c a, 1$ (3).

LIJPHART, Arend. (1999), Patterns of democracy: government forms and performance in thirty-six countries. New Haven, Yale University Press.

MAINWARING, Scott P. (2001), Sistemas partidários em novas democracias: o caso do Brasil. Porto Alegre/Rio de Janeiro, Mercado Aberto/FGV.

MAINWARING, Scott P. \& JONES, Mark P. (2001), 'The nationalization of parties and party systems: an empirical measure and an apllication to the Americas". Manuscrito não-publicado.

NICOLAU, Jairo M. (1997), "As distorções na representação dos estados na Câmara dos Deputados brasileira”. Dados, 40 (3), Rio de Janeiro, Iuperj.

(1996), Multipartidarismo e democracia: um estudo sobre o sistema partidário brasileiro (1985-1994). Rio de Janeiro, FGV.

. (2003), "A reforma da representação proporcional no Brasil”, in M. V. Benevides; P. Vannuchi e F. Kerche, Reforma política e cidadania, São Paulo, Fundação Perseu Abramo.

NORRIS, Pipa. (2004), Electoral engineering: voting rules and political behavior. Cambridge, Cambridge University Press.

REIS, Fábio Wanderley. (1993), "Estado liberal, projeto nacional, questão social". Planejamento e Políticas Públicas, 9.
SAMUELS, David J. \& SNYDER, Richard. (2001). "The value of a vote: malapportionment in comparative perspective". British Journal of Political Science, 31: 651-671, Cambridge University Press.

SOARES, Gláucio Ary D. (2001), A democracia interrompida. Rio de Janeiro, FGV. 


\section{A REPRESENTAÇÃO POLÍTICA DOS ESTADOS NA FEDERA- ÇÃO BRASILEIRA}

Márcia Miranda Soares e Luiz Cláudio Lourenço

\section{Palavras-chave}

Federalismo; Democracia; Representação política; Novos estados; Desigualdades regionais; Legislativo brasileiro.

Este artigo analisa a representação política no legislativo nacional brasileiro, dialogando com os autores que apontam a desproporcionalidade na representação da população dos estados como um dos problemas a ser equacionado na nossa democracia. A partir de considerações teóricas e dados empíricos procura-se demonstrar a singularidade da representação política em formas de Estado federativas; as imprecisões no diagnóstico das causas e das conseqüências da desigualdade na representação dos estados e o impacto da criação de novos estados sobre a representação política. As principais conclusões do trabalho levam à defesa, em nome da federação, de algum grau de desproporcionalidade na representação dos estados brasileiros na Câmara dos Deputados e ao diagnóstico de que a criação de estados pobres e pouco populosos é um fator relevante no aumento da desproporcionalidade, com impactos negativos não somente para a representação política, como também para as finanças públicas e as políticas sociais.

\section{LA REPRÉSENTATION POLITI- QUE DES ÉTATS DANS LA FÉ- DÉRATION BRÉSILIENNE}

\author{
Márcia Miranda Soares et Luiz \\ Cláudio Lourenço
}

\section{Mots-clés}

Fédéralisme; Démocratie; Représentation politique; Nouveaux États; Inégalités régionales; Législatif brésilien.

Cet article analyse la représentation politique dans le pouvoir législatif brésilien. Nous proposons un dialogue avec les auteurs qui indiquent la disproportion dans la représentation de la population des États comme l'un des problèmes à être résolus dans la démocratie brésilienne. À partir de ces considérations théoriques et de données empiriques, nous cherchons à démontrer la singularité de la représentation politique sous la forme d'États Fédératifs; les imprécisions du diagnostique des causes et des conséquences de l'inégalité dans la représentation des États; et l'impact de la création de nouveaux États dans la représentation politique. Les principales conclusions de ce travail conduisent à la défense, au nom de la fédération, d'un certain degré de disproportion dans la représentation des États brésiliens à la Chambre des Députés et au diagnostique selon lequel la création d'États pauvres et peu peuplés est un facteur relevant de l'augmentation de la disproportion, avec des impacts négatifs non seulement dans la représentation politique, mais aussi dans les finances publiques et les politiques sociales.

\section{THE POLITICAL REPRESEN- TATION OF STATES IN THE BRAZILIAN FEDERATION}

Márcia Miranda Soares and Luiz Cláudio Lourenço

\section{Keywords}

Federalism; Democracy; Political representation; New states; Regional unevenness; Brazilian legislative.

This paper analyses the political representation in the Brazilian national legislative, discussing authors that point out the disproportion in the representation of population in states as one of the problems to be worked out in the Brazilian democracy. Based on theoretical considerations and empirical data, we aim to demonstrate the singularity of the political representation in State federative kinds, the imprecise diagnostic of causes and consequences of the unevenness in representing the states, and the impact of forming new states on the political representation. The conclusions advocate the defense, in the name of the federation, of some degree of unevenness in representing Brazilian states in the House of Representatives and to the diagnosis that the generation of poor and populous states is a relevant factor to increase unevenness, with negative impacts not only on the political representation, but also on public finances and social policies. 